\title{
Zn(II) Complexes that Trigger a DNA Conformational Switch
}

\author{
Stephanie A. Sander and Janet R. Morrow*
}

Department of Chemistry, University at Buffalo, State University of New York, Buffalo, New York 14260, United States

*corresponding author

Email address: jmorrow@buffalo.edu 


\begin{abstract}
Several $\mathrm{Zn}(\mathrm{II})$ complexes are shown to produce a DNA conformational switch that involves dissociation of a fully complementary duplex into two hairpins. Of the three different pendent groups studied, a $\mathrm{Zn}$ (II) complex with a planar pendent connected directly to the macrocycle is the most effective at promoting the conformational switch. DNA duplexes of varying length and sequence are studied in order to examine the effect of lengthening AT tracts on conversion of duplex to hairpins. The role of hairpin structure in dissociated strands is also examined and shown to be a necessary component of an effective switch. Insight into the conformation switch is obtained through binding studies of the different $\mathrm{Zn}$ (II) complexes to DNA oligonucleotides that contain unpaired thymines by using surface plasmon resonance (SPR) and isothermal titration calorimetry (ITC).
\end{abstract}




\section{Introduction}

The design of metal complexes for the recognition of nucleic acid structure is an area of long-standing interest to inorganic chemists. There are several approaches that have been successful for the recognition of secondary structures of DNA by metal ion complexes. For example, some of the best known metal complex recognition agents for DNA have rigid shapes with multiple aromatic surfaces that interact with the planar surface of nucleobases. Excellent examples of this type of recognition include metal complexes that bind to planar G-tetrads in quadruplexes,[1] the recognition of three- and four-way helical junctions in DNA and RNA by dinuclear metal ion helicates, $[2,3]$ and metal complexes that selectively bind to DNA containing single-base bulges or base mismatches. $[4,5]$ A second type of metal ion recognition mode involves direct coordination of the metal ion center to one of the nucleobases. The most wellknown example of this is cisplatin which binds to the N7 of purine nucleobases.[6, 7] Another common type of recognition is binding to the N3 of deprotonated thymine or uracil nucleobases. Metal ions such as $\mathrm{Hg}(\mathrm{II})$,[8] or $\mathrm{Zn}$ (II)[9] bind to this site.

The dynamic nature of DNA structures further complicates the recognition process. For example, the Watson-Crick base pairs in DNA duplexes undergo a breathing motion that exposes the Watson-Crick face of the nucleobases to solvent.[10] DNA bulges and loop structures are also dynamic and may involve interconversion between different structural conformers. This makes recognition even more challenging given that the metal ion complex might perturb DNA structure and dynamics. In the most extreme case, binding of the metal ion complex would promote conversion of one secondary structure to a different one to give a DNA switch.[11] Here we explore methods to convert between duplex DNA and hairpin DNA with metal complexes to further explore the factors which are important in promoting this conformational switch.

Interesting cases of metal ion complex binders that take into account the dynamic nature of DNA have been reported. For example, Nordén and co-workers reported on a DNA binder that was inspired by natural antibiotic intercalators[12-14] and by synthetic polyintercalators which display slow dissociation constants from poly $(\mathrm{dG}-\mathrm{dC})_{2}$ DNA.[15] His group studied a ruthenium complex that threaded through the DNA helix. $[16,17]$ The binuclear ruthenium complex, $[\mu-$ (11,11 '-bis(dipyrido[3,2-a:2'3'-c]phenazinyl)(1,10-phenatholine) $\left.\left.\mathrm{Ru}_{2}\right)\right]^{4+}$, initially interacted as a dA-dT groove binder before it threaded into the helix.[18] The act of threading within the helix 
was a very slow process, presumably because the helix needed to partially denature to accommodate the metal complex. The ligand aromatic rings on either end of the threaded complex acted as anchors to give tight binding of the complex to DNA.[19] Unthreading of the complexes required correspondingly significant and unfavorable conformational changes in the DNA.[20]

Metal complexes have also been shown to promote the conversion of duplex DNA into noncanonical DNA secondary structures or vice-versa. For example, $\mathrm{Hg}(\mathrm{II})$ ions form interstrand thymine crosslinks that favor duplex over hairpin DNA for certain sequences.[21] Another example features a duplex containing a G-rich portion which can reversibly form Gquadruplexes.[22] Formation of the G-quadruplex is promoted through the stabilization of the structure by $\mathrm{Pb}(\mathrm{II})$ ions. The reverse reaction, G-quadruplex conversion to duplex DNA, proceeds upon addition of the ligand 1,4,7,10-tetraazacyclododecane-1,4,7,10-tetraacetic acid (DOTA) through the sequestration of the $\mathrm{Pb}(\mathrm{II})$ ion. This DNA switch demonstrates the conversion between two very different secondary structures and has potential application for the determination of $\mathrm{Pb}$ (II) ion with detection limits as low as $20 \mathrm{nM}$.[22] Notably, this switch relies on a duplex which contains two dangling ends or 'toeholds" at both 5' and 3' ends of one strand. The presence of a toehold is typically used as a recognition point to increase the propensity of the duplex to form a new structure upon binding of a small molecule.[23-25]

Here, we introduce several $\mathrm{Zn}(\mathrm{II})$ complexes which convert fully complementary DNA to hairpin form. The switch generally consists of an AT rich duplex which produces A- and Tloop hairpins and is driven by the propensity of $\mathrm{Zn}$ (II) complexes to bind to unpaired thymines in non-canonical structures. That $\mathrm{Zn}$ (II) tetraazamacrocyclic complexes act as recognition agents for thymine in nucleotides and single-stranded oligonucleotides was originally shown by Kimura and co-workers.[9] Studies showed that the deprotonated imide of the thymine nucleobase interacted selectively with the $\mathrm{Zn}$ (II) center in these complexes.[9] While this interaction is selective for thymine over other nucleobases, the binding strength of the parent $\mathrm{Zn}$ (II) complex of cyclen $(1,4,7,10$-tetrazacyclododecane) for uridine or thymine is relatively weak. Dissociation constants for thymidine or uridine nucleosides and $\mathrm{Zn}$ (cyclen) are in the milimolar range.[26] Addition of aromatic pendent groups on the macrocycle increases the binding strength to thymine. Selective binding of the $\mathrm{Zn}$ (II) cyclen macrocycle to unpaired thymine bases is maintained for several different types of aromatic pendent groups.[9, 27] 
The development of $\mathrm{Zn}$ (II) complexes for selective binding of unpaired thymine bases which are in unusual DNA structures is more complicated. For example, the interaction of $\mathrm{Zn}$ (II) complexes with unpaired thymines in non-canonical context including those in bulged DNA and quadruplex DNA has been reported.[28-30] Binding of a $\mathrm{Zn}$ (II) complex to thymine mismatches has also been studied.[31] Applications include of $\mathrm{Zn}$ (II) cyclen binding to thymine mismatches include enhanced specificity of DNA polymerase chain reactions, and more accurate analysis of single nucleotide polymorphisms.[32-34] For recognition of such non-canonical DNA, the pendents may interact with the unpaired thymines as they do in simple oligonucleotides, or with other elements in the DNA structure.[29] Notably, there are restrictions on the size and structure of the pendent that optimize the selective binding of $\mathrm{Zn}$ (II) complexes to unpaired thymine versus duplex DNA. Zn(II) complexes with pendents containing two fused rings show increased binding for non-canonical thymine over duplex DNA.[9, 27] In contrast, a pendent with a simple benzene derivative did not increase binding strength significantly.[35] Pendent groups with three fused rings are not selective for unpaired thymines because they typically bind through intercalation into the DNA duplex.[9] For this reason, only two-ring pendent groups on the $\mathrm{Zn}(\mathrm{II})$ complexes were used in this study. Rings with electronegative heteroatoms in the pendent were studied in order to create an electron deficient pi system,[36] which may increase stacking interactions with the thymine or other nucleobases.[37] Previous studies verified the importance of the heteroatom in the case of a $\mathrm{Zn}$ (II) complex with a quinoline ring pendent which showed a much greater binding affinity to T-bulge DNA in comparison to a naphthyl pendent group.[30]

We previously communicated on a $\mathrm{Zn}$ (II) complex that reversibly switched the conformation of a DNA duplex into its respective hairpin conformations at moderate ratios of the metal complex to DNA.[11] Interestingly, the switch failed to destabilize a similar DNA duplex whose respective single strands were unable to form a hairpin secondary structure (Scheme 1). The conversion was promoted only by the $\mathrm{Zn}(\mathrm{II})$ complex, and not by $\mathrm{Fe}(\mathrm{II})$ or $\mathrm{Cu}$ (II) complexes. Here we study additional DNA sequences in conformational switching. We also compare three different $\mathrm{Zn}$ (II) complexes to gain insight into the role of the pendent group including the connectivity of each pendent to the cyclen macrocycle in promoting the duplex to hairpin switch. As shown here, a rigid pendent group with no connecting linker enhances conversion of the duplex to hairpin form by the $\mathrm{Zn}$ (II) complex most effectively. 


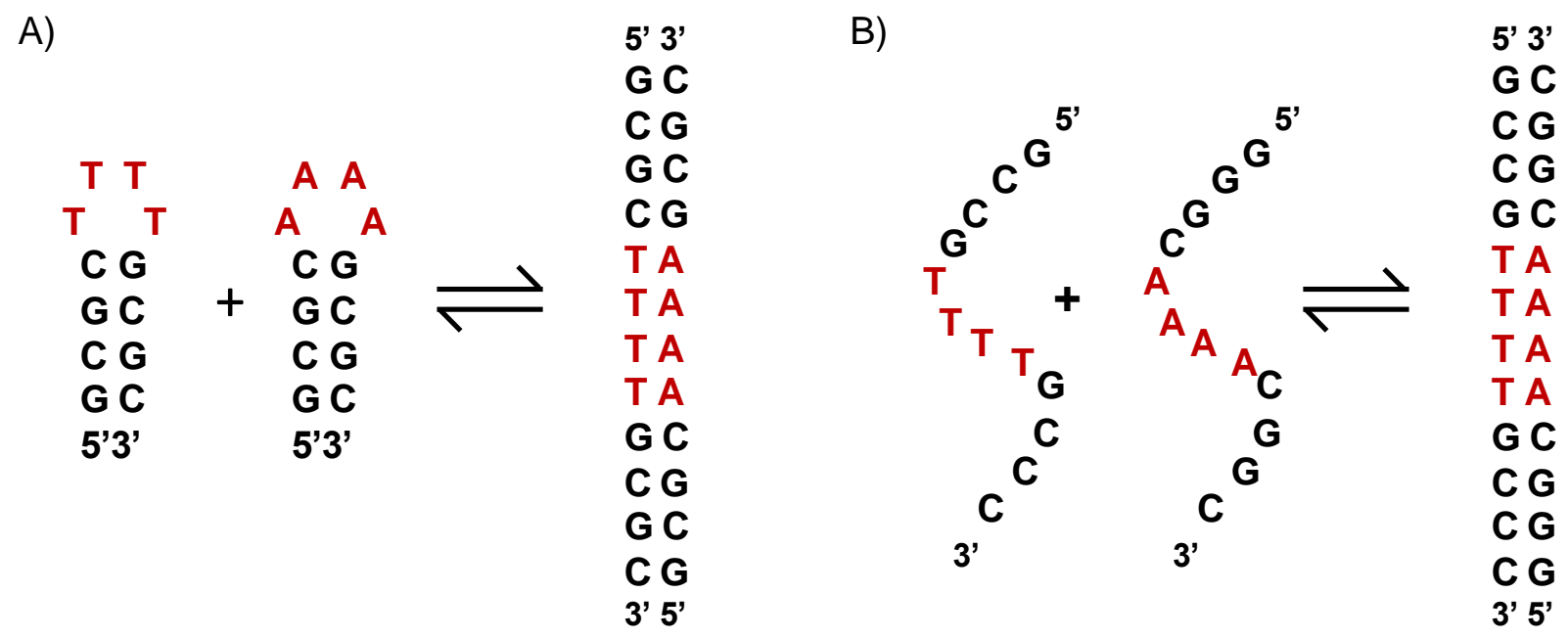

Scheme 1. DNA structures A) HP-T4, HP-A4 and D-4 and B) SS-T4, SS-A4 and D-4*.

\section{Results}

\subsection{Macrocyclic complexes}

The $\mathrm{Zn}(\mathrm{II})$ complexes studied here each have a fused two-ring pendent group which is attached to a cyclen macrocycle (Scheme 2) (cyclen =1,4,7,10-tetraazacyclododecane). As shown previously, the macrocycles bind tightly to the $\mathrm{Zn}$ (II) ion to give complexes which are $>90 \%$ intact even at micromolar concentrations of $\mathrm{Zn}$ (II) and macrocycle at neutral $\mathrm{pH} .[28-30]$ The pendents have distinct ring structures as well as connections to the macrocycle through different types of linkers including a methylene (ML), sulfone (SL) or direct attachment (DL). The rings are either planar (ML, DL) or have groups that are out of the plane of the rings such as SL. Notably, the dimethylamino group in dansyl groups is generally rotated with respect to the plane of the aromatic rings. Both the linker and the aromatic group are expected to influence the interaction of the pendent with the thymine nucleobases in the DNA structures. 

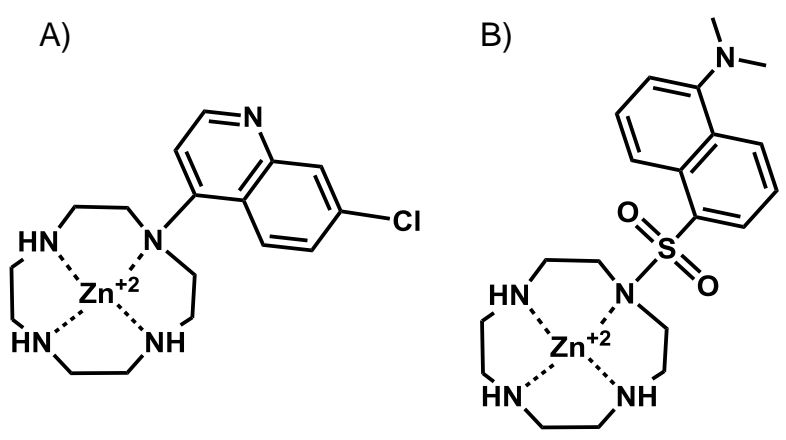

C)

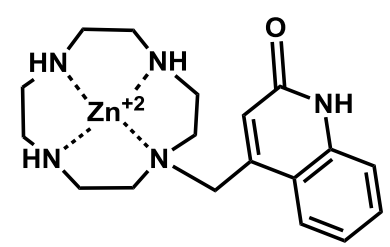

Scheme 2. Zn(II) complexes A) Zn(DL), B) Zn(SL) and C) Zn(ML).

\subsection{Native polyacrylamide gel electrophoresis (PAGE)}

Native polyacrylamide gel electrophoresis (PAGE) studies were carried out to monitor structural changes upon binding of the $\mathrm{Zn}$ (II) complexes. The native hairpin bands migrate through the gel more rapidly than the native duplex (Fig. 1). The distinct migration rates of the different secondary structures allows for analysis of duplex destabilization. Previous studies reported evidence for hairpin formation of single stranded DNA upon denaturation of D-4 through FRET studies.[11]

Native polyacrylamide gels show that Zn(ML) destabilizes the D-4 duplex (Fig. 1C) under conditions similar to those used for studies of $\mathrm{Zn}(\mathrm{DL})$. The new band on the gel produced by addition of $\mathrm{Zn}(\mathrm{ML})$ co-migrates with native hairpins, supporting a conformational switch from the duplex to hairpin form. However, even at a 15-fold excess (molar ratio) of $\mathrm{Zn}(\mathrm{ML})$ to D-4 duplex, complete disappearance of the duplex is not observed.

Destabilization of the D-4 duplex was also observed with Zn(SL) (Fig. 1B). A new band which co-migrates with native hairpin bands is observed. Essentially complete destabilization of the D-4 duplex is observed at a 15 fold excess of $\mathrm{Zn}(\mathrm{SL})$ to duplex. The increased destabilization by $\mathrm{Zn}(\mathrm{SL})$ still does not match that observed with $\mathrm{Zn}(\mathrm{DL})$ which shows disappearance of the duplex band at a 1:8 ratio. 

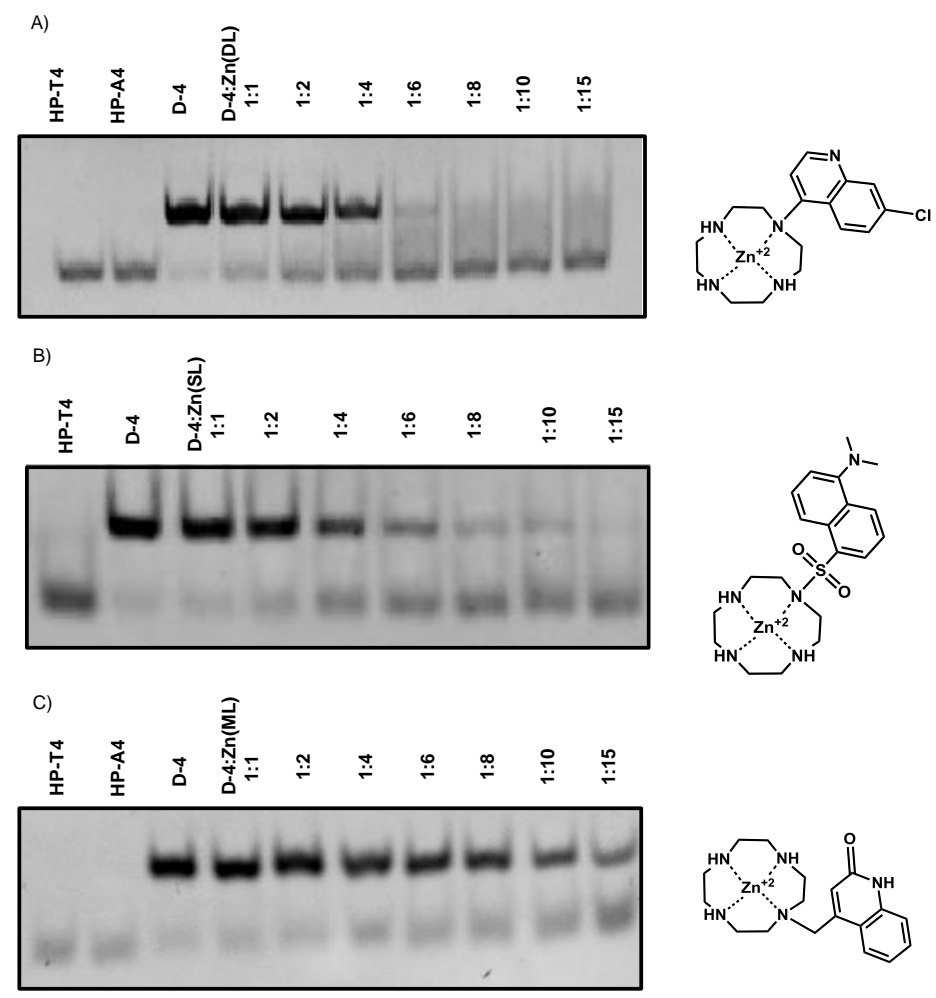

Fig. 1. Native polyacrylamide gel electrophoresis of D-4 duplex with A) increasing ratios of $\mathrm{Zn}(\mathrm{DL}) \mathrm{B}$ ) increasing ratios of $\mathrm{Zn}(\mathrm{SL})$ and $\mathrm{C}$ ) increasing ratios of $\mathrm{Zn}(\mathrm{ML})$. All samples were prepared with $25 \mu \mathrm{M}$ DNA, $0.080 \mathrm{M} \mathrm{NaCl}, 0.020 \mathrm{M}$ HEPES $\mathrm{pH}$ 7.5. Oligonucleotides are shown in Scheme 1.

The interaction of the $\mathrm{Zn}$ (II) complexes with the HP-T4 hairpin loop was studied to better understand the potential mechanism of the conformational switch shown in Figure 1. The hairpin migration was studied by using native gels to determine if the $\mathrm{Zn}$ (II) complexes bound to the hairpin and/or changed its conformation which would be observed as a change in the migration rate of the DNA on the gel. Changes were observed in the native gel for HP-T4 in the presence of high ratios of $\mathrm{Zn}(\mathrm{DL})$ to hairpin as shown by PAGE analysis (Figure S1). The smearing of the DNA band on the gel is attributed to binding of the $\mathrm{Zn}(\mathrm{DL})$ complex to the hairpin. The corresponding smears with hairpin DNA are also observed to some extent on the native gels with duplex and this complex. In contrast, there was minimal change in the hairpin migration when combined with excess $\mathrm{Zn}(\mathrm{ML})$ or $\mathrm{Zn}(\mathrm{SL})$ (Fig. S1). Further studies to measure the effect of the $\mathrm{Zn}$ (II) complexes on the stability of the hairpins by using thermal optical melting experiments were not feasible due to the high melting temperature of the hairpins. 


\subsection{Surface plasmon resonance (SPR)}

Hairpin binding studies were carried out by using surface plasmon resonance (SPR). The relatively low concentrations of complex and DNA that are utilized in SPR in comparison to isothermal titration calorimetry (ITC) are an advantage for monitoring tight binding. In addition, at the higher concentrations typically required for ITC, higher order equilibria may be favored. Previous studies gave a dissociation constant of $6.3 \mu \mathrm{M}$ and $76 \mu \mathrm{M}$ from fitting of SPR data to a 2:1 stoichiometry for $\mathrm{Zn}(\mathrm{DL})-\mathrm{HP}-\mathrm{T} 4 .[11]$

Studies on the binding of the Zn(ML) complex to the HP-T4 hairpin by SPR gave an approximately 10-fold weaker dissociation constant $\left(\mathrm{K}_{\mathrm{d}}=56 \pm 2 \mu \mathrm{M}\right)$ when compared with the Zn(DL)-HP-T4 binding interaction (Fig. S2, 2A \& Table S1). The 1:1 stoichiometry of this interaction was also different than the 2:1 stoichiometry observed for $\mathrm{Zn}(\mathrm{DL})$ with the hairpin. The $\mathrm{Zn}(\mathrm{SL})$ complex also bound to HP-T4 with a 1:1 stoichiometry but exhibited an even weaker $\mathrm{K}_{\mathrm{d}}$ of $150 \pm 30 \mu \mathrm{M}$ (Fig. $2 \mathrm{~B} \&$ Table S1). The 1:1 stoichiometry suggests that a second complex cannot bind to more than one thymine in the more compact hairpin structure.
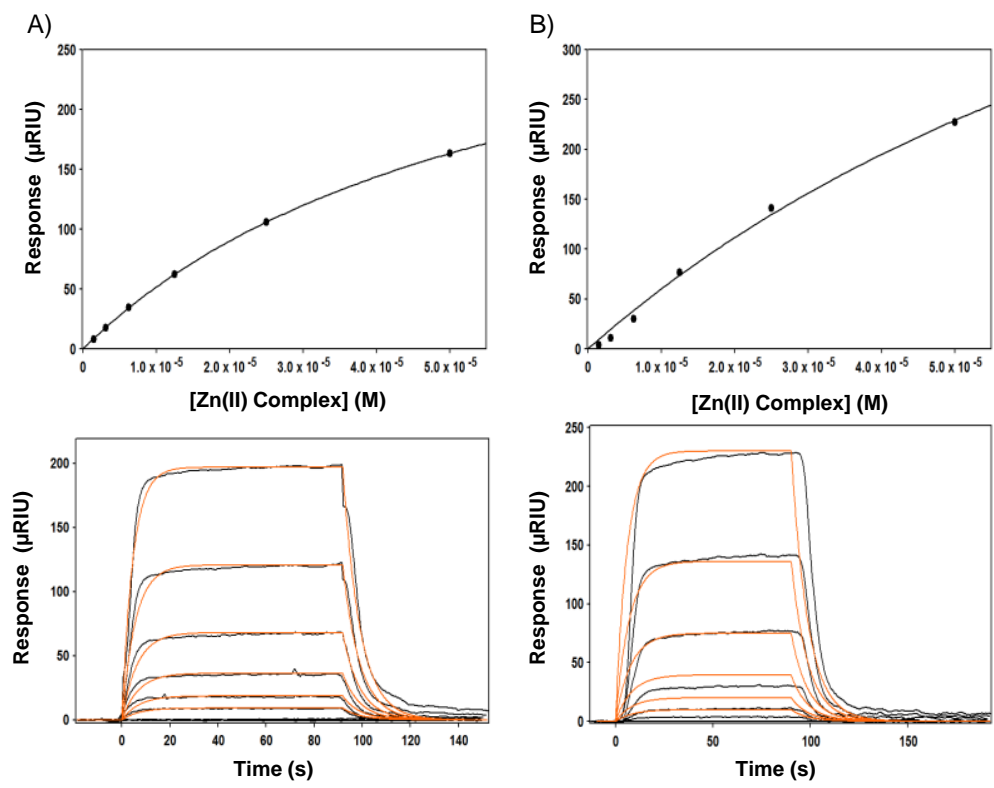

Fig. 2. Surface plasmon resonance studies with HP-T4 and A) Zn(ML) and B) Zn(SL). Top: Change in response ( $\mu \mathrm{RIU}$ - refractive index units) versus $\mathrm{Zn}(\mathrm{II})$ complex concentration with data fit to binding isotherms. Bottom: Change in response ( $\mu$ RIU) versus time to determine 
on/off rate constants. Concentration of $\mathrm{Zn}(\mathrm{II})$ complex ranged from $1.5 \mu \mathrm{M}-50 \mu \mathrm{M}$. All samples were prepared in $0.10 \mathrm{M} \mathrm{NaCl}, 0.020 \mathrm{M}$ HEPES pH 7.5 and $0.05 \%$ tween.

\subsection{Isothermal titration calorimetry (ITC)}

Interactions with a single-stranded DNA sequence with multiple adjacent thymines (SST4) were studied to give insight into the binding of the complexes to thymine in a structurally flexible context. This DNA sequence was studied to determine the stoichiometry of binding to multiple adjacent thymines in a linear context. Binding of the $\mathrm{Zn}$ (II) complexes to the singlestranded SS-T4 may resemble that of binding to the D-4 duplex as it denatures. ITC provides a convenient way to monitor binding in solution, but requires higher concentrations of DNA and complex than in SPR in order to obtain a measurable signal.

$\mathrm{Zn}(\mathrm{SL})$ binds to SS-T4 with 2:1 stoichiometry with dissociation constants of $\mathrm{K}_{\mathrm{d} 1}=120 \pm$ $6 \mu \mathrm{M}$ and $\mathrm{K}_{\mathrm{d} 2}=0.8 \pm 0.3 \mathrm{mM}$ (Fig. 3A \& Table S1). Zn(ML) binds to SS-T4 with 1:1 stoichiometry with $\mathrm{K}_{\mathrm{d}}=83 \pm 8 \mu \mathrm{M}$ (Fig. 3B \& Table S1). The binding of these two complexes is weaker than that reported for $\mathrm{Zn}(\mathrm{DL})\left(\mathrm{K}_{\mathrm{d}}=23\right.$, and $\left.56 \mu \mathrm{M}\right)$ to SS-T4. Additional studies were performed with cytosine-rich single strands (C5) as a control. The data was consistent with very weak interactions between $\mathrm{Zn}$ (II) complexes and C5 that could not be fit to binding curves (Fig. S3).
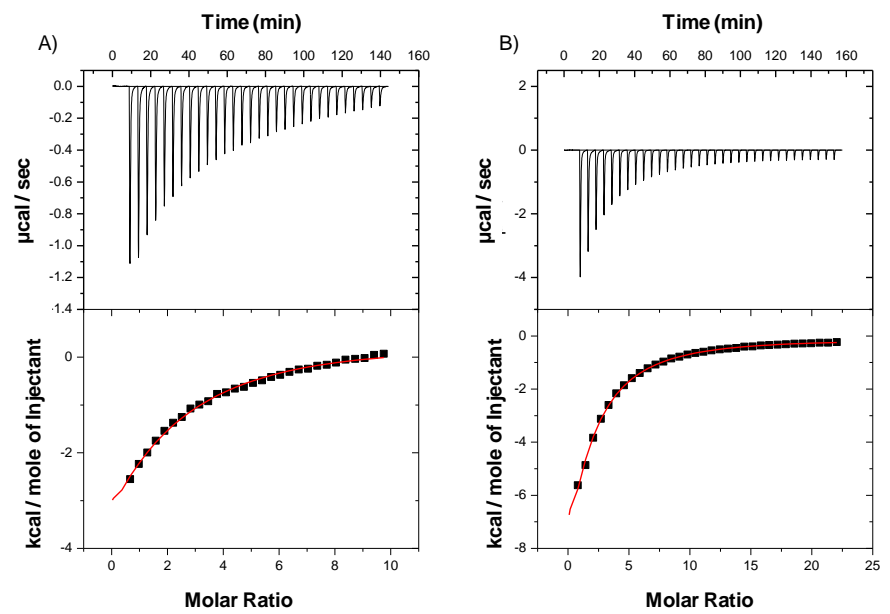

Fig. 3. Isothermal calorimetry titrations with SS-T4 and A) Zn(SL) and B) Zn(ML). All samples were prepared with $25 \mu \mathrm{M}$ DNA, 0.080 M NaCl, 0.020 M HEPES pH 7.5. 


\subsection{DNA sequences}

$\mathrm{Zn}(\mathrm{DL})$ was chosen for further studies to capitalize on its effectiveness in promoting conversion of duplex to hairpins. A series of duplexes with varying numbers of dA-dT base pairs were treated with this complex. Duplexes D-3, D-4, D-7, D-4* and D-7* (Table 1) were studied both in the presence and absence of $\mathrm{Zn}(\mathrm{DL})$. Notably, the duplexes labeled D-3, D-4, and D-7 are produced from two DNA strands that contain a fully complementary GC stem and thus may form hairpin structures (Scheme 1A).[38] In contrast, D-4* and D-7* are formed from two DNA strands that lack complementarity in the GC sequence, decreasing the likelihood of forming hairpins (Scheme 1B). Studies using native PAGE showed that, for all sequences, two complementary DNA single-strands hybridized to form a duplex in the absence of Zn(II) complexes (Fig. 1, S1, S4, S5 and S6).

Table 1. Single stranded and duplex DNA sequences, and thermal melting temperatures

\begin{tabular}{|c|c|c|c|}
\hline $\begin{array}{l}\text { Single } \\
\text { Strand }\end{array}$ & Sequence & Duplex & $\begin{array}{l}\text { Duplex } \\
\mathrm{T}_{\mathrm{m}}\left({ }^{\circ} \mathrm{C}\right)\end{array}$ \\
\hline HP-T3 & \multirow{2}{*}{$\begin{array}{l}\text { 5' GCG CT T T GC GC 3' } \\
\text { 3' CGC GAA ACG CG 5' }\end{array}$} & \multirow[t]{2}{*}{ D-3 } & \multirow[t]{2}{*}{38.6} \\
\hline HP-A3 & & & \\
\hline HP-T4 & \multirow{2}{*}{$\begin{array}{l}\text { 5' GCG CT T T T G CGC 3' } \\
\text { 3' CGC GAA AAC GCG 5' }\end{array}$} & \multirow[t]{2}{*}{ D-4 } & \multirow[t]{2}{*}{41.2} \\
\hline HP-A4 & & & \\
\hline HP-T7 & \multirow{2}{*}{$\begin{array}{l}\text { 5' GCG C T T T T T T T G CGC 3, } \\
\text { 3' CGC GAA AAA AAC GCG 5' }\end{array}$} & \multirow[t]{2}{*}{ D-7 } & \multirow[t]{2}{*}{53.1} \\
\hline HP-A7 & & & \\
\hline SS-T4 & \multirow{2}{*}{$\begin{array}{l}\text { 5' GCC G T T T TG CCC 3' } \\
\text { 3' CGG CAA AAC GGG 5' }\end{array}$} & \multirow[t]{2}{*}{ D-4* } & \multirow[t]{2}{*}{53.1} \\
\hline SS-A4 & & & \\
\hline SS-T7 & \multirow{2}{*}{$\begin{array}{l}\text { 5' GCC GTT T TT TT G CCC 3', } \\
\text { 3' CGG CAA AAA AAC GGG 5', }\end{array}$} & \multirow[t]{2}{*}{ D-7* } & \multirow[t]{2}{*}{55.1} \\
\hline SS-A7 & & & \\
\hline
\end{tabular}

$\mathrm{T}_{\mathrm{m}}$ values recorded for $2 \mu \mathrm{M}$ duplex DNA, 0.080 M NaCl, 0.020 M HEPES pH 7.5. Standard deviations in melting temperature for all sequences are less than $10 \%$.

\subsubsection{Thermal melts}

The stability of the duplexes depends on the base sequence and on the secondary structure (hairpin) formation in single-strands. For example, the D-4 and D- $4 *$ duplexes vary 
only in the GC sequence which influences the formation of hairpin structures in their respective single-strands. The thermal melting temperature $\left(\mathrm{T}_{\mathrm{m}}\right)$ of the $\mathrm{D}-4$ duplex is $41{ }^{\circ} \mathrm{C}$ while the D- $4 *$ duplex is $53{ }^{\circ} \mathrm{C}$. Moreover, as the length of the A-T tract increases, so does the thermal stability of each of the duplexes studied. The native melting temperatures of the duplexes range from 39 ${ }^{\circ} \mathrm{C}$ to $53{ }^{\circ} \mathrm{C}$ for D-3 to D-7, respectively (Table 1 ). The increasing thermal stability of duplexes in this series corresponds with an increase in the number of base pairs.

\subsubsection{Native polyacrylamide gel electrophoresis (PAGE)}

The effect of DNA sequence on the conformational change was studied with $\mathrm{Zn}(\mathrm{DL})$. The shortest duplex studied was D-3 (Table 1). This duplex was chosen because the thymine containing single strand, HP-T3, is known to form a stable hairpin structure while any fewer than 3 nucleobases in the loop of a hairpin are usually less stable.[38-40] Complete conversion of D-3 into a product that co-migrated with the hairpin products was observed at a 1:6 DNA:Zn(II) complex mole ratio (Fig. S4). However, the optical melting temperature $\left(\mathrm{T}_{\mathrm{m}}\right)\left(39^{\circ} \mathrm{C}\right.$ at $\left.2 \mu \mathrm{M}\right)$ of the D-3 duplex is low and some dissociation was observed even without $\mathrm{Zn}$ (II) complex. Thermal stability was improved by addition of more dA-dT base pairs making D-4 a better duplex for development as a switch. Increasing the dA-dT tract in the duplex even further was studied.

Duplexes with seven consecutive AT base pairs were examined including D-7 and D-7* (Table 1). Also studied was a duplex with four AT base pairs, similar to D-4, but with a different GC sequence that would inhibit hairpin formation upon melting of the duplex. This duplex has a correspondingly higher thermal melting temperature. As shown in Fig. S5-S6, the D-4* duplex did not dissociate in the presence of $\mathrm{Zn}(\mathrm{DL})$ even at a 10:1 $\mathrm{Zn}$ (II) complex:DNA ratio. Neither did the D-7* duplex dissociate in the presence of a 10:1 excess of $\mathrm{Zn}(\mathrm{DL})$. In contrast, the D-7 duplex was converted into a faster migrating form of DNA in the presence of excess of $\mathrm{Zn}(\mathrm{DL})$.

\section{Discussion}

The greater destabilization of the D-4 DNA duplex by $\mathrm{Zn}(\mathrm{DL})$ in comparison to Zn(ML) and $\mathrm{Zn}(\mathrm{SL})$ correlates with the stronger binding of $\mathrm{Zn}(\mathrm{DL})$ to unpaired thymines in both singlestranded DNA and in hairpin DNA. Denaturation presumably involves binding of the $\mathrm{Zn}(\mathrm{II})$ 
complexes to thymines that are transiently unpaired due to helical breathing. DNA breathing is important in the destabilization of duplex DNA. The opening and closing of duplex DNA, primarily in areas where there are long tracts of dA-dT, may be amenable for the interaction of the $\mathrm{Zn}$ (II) complexes with the Watson Crick face of thymine (Scheme 3). Single-stranded DNA provides an approximate, although not ideal model, of these relatively flexible thymine runs.

Fitting of binding isotherms is most consistent with micromolar binding of $\mathrm{Zn}(\mathrm{DL})$ to two of the four thymines in SS-T4. In contrast, Zn(ML) binds with a 1:1 stoichiometry to SS-T4, and $\mathrm{Zn}(\mathrm{SL})$ has a 2:1 stoichiometry, but with a very weak second dissociation constant. If the tightest dissociation constants are compared, $\mathrm{Zn}(\mathrm{ML})$ and $\mathrm{Zn}(\mathrm{SL})$ bind 4-fold and 6-fold less strongly than does $\mathrm{Zn}(\mathrm{DL})$. The most likely reason that $\mathrm{Zn}(\mathrm{DL})$ is superior in this regard is that the planar pendent is directly connected to the macrocycle so that stacking on thymine is sterically efficient. In comparison, $\mathrm{Zn}(\mathrm{SL})$ has a non-planar aromatic group and a sulfone linker. The $\mathrm{Zn}(\mathrm{ML})$ has a planar pendent, but also has an additional methylene in the linker. This added flexibility to the pendent may decrease the propensity to interact with bound thymine groups leading to weaker binding. Both the binding strength and the stoichiometry of $\mathrm{Zn}(\mathrm{DL})$ adducts of SS-T4 are consistent with this complex being the most effective for promoting the DNA switch. In particular, binding of more than one $\mathrm{Zn}(\mathrm{DL})$ complex to multiple thymines in a thymine tract may be key to unzipping the duplex. Notably, the relative values of the two dissociation constants for the $1: 1$ and 2:1 $\mathrm{Zn}(\mathrm{DL})$ adduct with SS-T4 (23 and $56 \mu \mathrm{M}$, respectively) suggest a lack of cooperative interaction with respect to a two site receptor binding model.[41] Helix denaturation, however, is normally a cooperative transition and one could imagine that binding of multiple thymines in the AT run would facilitate this process. 


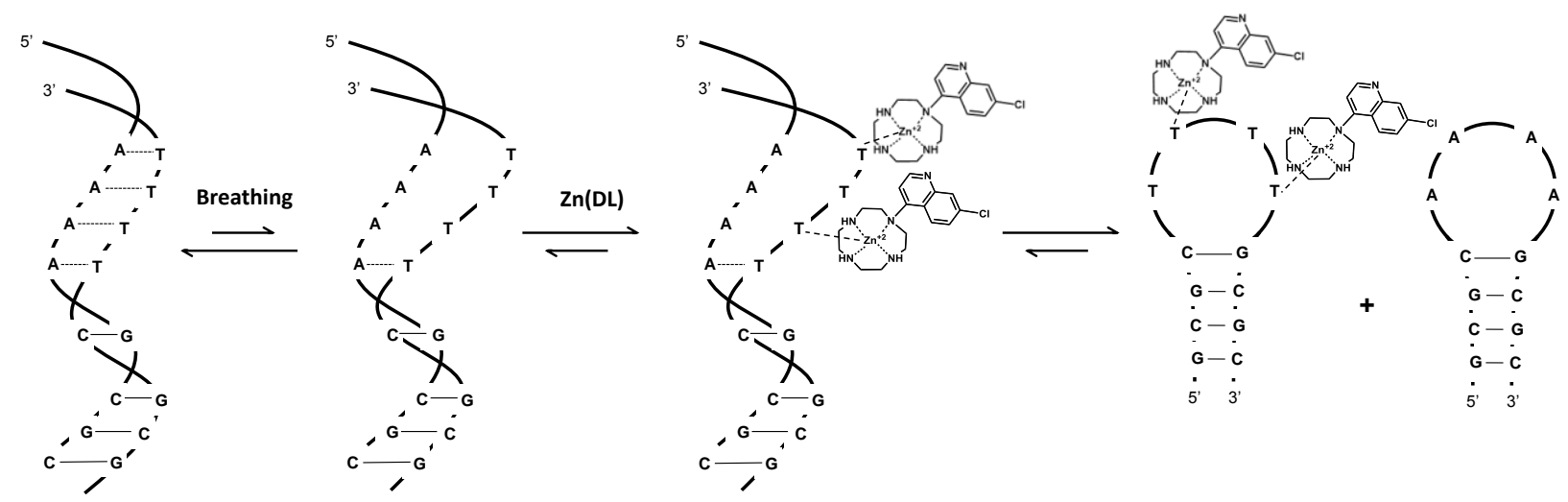

Scheme 3. Representation of DNA breathing, $\mathrm{Zn}(\mathrm{DL})$ binding and denaturing helix forming respective T- and A-hairpin loops.

$\mathrm{Zn}$ (II) complexes may modify the position of the equilibrium between duplex and hairpin DNA by accelerating denaturation of DNA in the forward direction through binding of the complexes to the transiently unpaired thymines, but also by binding to the hairpin loops and slowing re-association of the two strands (Scheme 3). In this regard, Zn(DL) binds tightly to the single stranded thymines, but even more tightly to the thymine containing hairpin, HP-T4. This suggests that hairpin interactions dominate for this complex. Once again two dissociation constants are measured, although the second one is 10-fold weaker than the first. That a 2:1 interaction is observed for the $\mathrm{Zn}(\mathrm{DL})$ complex and not for the other two complexes suggests that the more compact pendent group of DL allows for binding of two complexes to the thymines of the hairpin loop. In contrast, neither $\mathrm{Zn}(\mathrm{SL})$ nor $\mathrm{Zn}(\mathrm{ML})$ form 2:1 adducts with the hairpin loop, consistent with the constrained nature of the thymines in the loop. These complexes have roughly similar dissociation constants for single stranded versus hairpin DNA, suggesting that neither binding event dominates.

The bifunctional nature of the $\mathrm{Zn}(\mathrm{II})$ complexes makes it important to consider the effect of both the $\mathrm{Zn}(\mathrm{II})$ center and the pendent group on DNA binding strength. The different pendent groups not only affect binding to the nucleic acid through base stacking interactions, but also influence the Lewis acidity of the $\mathrm{Zn}$ (II) center. The Lewis acidity of the $\mathrm{Zn}$ (II) center modulates binding strength as shown by the correlation between $\mathrm{Zn}$-water $\mathrm{p} K_{\mathrm{a}}$ values and thymine binding in simple macrocyclic complexes of $\mathrm{Zn}$ (II).[42] Generally, the lower the $\mathrm{p} K_{\mathrm{a}}$ of the $\mathrm{Zn}$-water, the higher the Lewis acidity of the $\mathrm{Zn}$ (II) center and the more strongly the complex binds thymine. Here, the $\mathrm{p} K_{\mathrm{a}}$ values for $\left[\mathrm{Zn}(\mathrm{DL})\left(\mathrm{OH}_{2}\right)\right]^{2+},\left[\mathrm{Zn}(\mathrm{ML})\left(\mathrm{OH}_{2}\right)\right]^{2+}$ and $\left[\mathrm{Zn}(\mathrm{SL})\left(\mathrm{OH}_{2}\right)\right]^{2+}$ are $8.44,8.30$ 
and 7.93, respectively.[30] These data suggests that the strongest interaction with the thymine containing DNA would be with $\mathrm{Zn}(\mathrm{SL})$ based on Lewis acidity, but this is not the case here. Rather, the interaction which dominates binding and duplex denaturation must be the pendent interaction and not the strength of direct coordination of $\mathrm{Zn}(\mathrm{II})$ to thymine.

The role of aromatic pendent groups in stacking on top of the thymine along with $\mathrm{Zn}$ (II) binding to the $\mathrm{N} 3$ of thymine has been emphasized in the past. This view has been supported by a crystal structure of $\mathrm{Zn}(\mathrm{II})$ complexes containing pendents with large planar groups such as acridine that show the acridine pendent and thymine stacked parallel in an apparent pi-pi interaction.[26] However, for the two-ring pendents studied here, the orientation of the pendent with respect to the bound thymine may not necessarily be parallel. Smaller ring interactions may involve perpendicular or offset orientations.[37] The dansyl group in particular which contains non-planar substituents, is unlikely to stack in the same manner as a planar group. Notably, the bulky dansyl group on $\mathrm{Zn}(\mathrm{SL})$ gives rise to a complex that interacts strongly with the accessible thymines in the human teleromeric G-quadruplex loops, but not to a more tightly constrained single-thymine bulge in a DNA duplex or even the thymine in loop structure as shown here.[28, 30]

The majority of the duplexes studied here were destabilized in the presence of $\mathrm{Zn}(\mathrm{DL})$. The duplexes, including D-3, D-4, and D-7, showed some degree of denaturation at a 1:10 DNA:Zn(II) complex mole ratio, as observed by studies using gel electrophoresis. As expected, there was a decrease in the extent of denaturation by $\mathrm{Zn}(\mathrm{DL})$ with the longer and more stable duplexes. Regardless of the degree of destabilization of these duplexes, the product of such a process most likely gives T- and A-loop hairpins. The formation of hairpin structures for thymine containing sequences (HP-T3, HP-T4, HP-T7) has been confirmed under conditions similar to those here.[38] In addition, the single DNA strands HP-T3, HP-T4, HP-T7, HP-A3, HP-A4, HP-A7 (Table 1) stain on the gel with ethidium bromide, supporting the formation of a stem that binds the fluorescent dye. Denaturation of the duplexes produces bands on the gels that stain with ethidium bromide and co-migrate with the hairpins. Only the duplexes D-4* (Fig. S5A) and D-7* (Fig. S5B) showed no evidence of denaturation. These duplexes do not have sequences that would give hairpin loops. This suggests that binding of $\mathrm{Zn}(\mathrm{DL})$ to the thymines of hairpin loops is important in promoting the duplex to hairpin switch. 


\section{Conclusions}

Structural differences of the pendent group are of primary importance in $\mathrm{Zn}(\mathrm{II})$ complexes that promote duplex to hairpin switches. A planar aromatic that is directly attached to the macrocycle gives a $\mathrm{Zn}$ (II) complex that binds strongly to two unpaired thymines in a fourthymine sequence both in unstructured DNA and in hairpin loops. In this manner, the $\mathrm{Zn}$ (II) complex may mediate the switch by destabilization of the duplex and by binding to the hairpin loop to prevent re-hybridization. This postulate is supported by the fact that DNA duplexes that are effectively denatured by $\mathrm{Zn}(\mathrm{DL})$ have single-strands that form hairpin loops. Sequences with similar thermal melting temperatures that do not have single-strands with sequences that form hairpins, are not denatured by the $\mathrm{Zn}(\mathrm{DL})$ complex. Thus the switch was most efficient with duplex sequences which were able to convert into single-strands which form their own stable secondary structures. Macrocyclic complexes with aromatic pendent groups attached through more flexible linkers do not bind to unpaired thymines as tightly, and are not as effective at promoting the DNA duplex to hairpin conversion. The binding of two $\mathrm{Zn}(\mathrm{DL})$ complexes to DNA containing multiple adjacent unpaired thymines may be important in mediating effective unzipping of the duplex.

\section{Experimental}

\subsection{Materials}

All ligands, DL,ML and SL and their respective $\mathrm{Zn}(\mathrm{II})$ complexes were synthesized as reported previously.[28, 30, 43] All DNA was purchased from Integrated DNA Technologies (IDT) (www.idtdna.com).

\subsection{Native polyacrylamide gel electrophoresis (PAGE)}

All DNA was purchased from Integrated DNA Technologies (IDT) (www.idtdna.com). Samples contained $25 \mu \mathrm{M}$ DNA, 0.080 M NaCl and 0.020 M HEPES buffer, $\mathrm{pH} 7.5$ and variable concentrations of $\mathrm{Zn}(\mathrm{DL})$ which were incubated then added to a sucrose loading buffer (40\%). Samples were run on a polyacryalamide gel $\left(20 \%\right.$ at $\left.100 \mathrm{~V}, 22{ }^{\circ} \mathrm{C}\right)$ and stained in an ethidium 
bromide solution $(25 \mathrm{mM})$ before being imaged on a BIORAD PharosFX pro imager. Percent destabilization was analyzed through the PharosFX program.

\subsection{Surface Plasmon resonance (SPR)}

The binding affinity of $\mathrm{Zn}(\mathrm{DL}), \mathrm{Zn}(\mathrm{ML})$ and $\mathrm{Zn}(\mathrm{SL})$ to HP-T4 hairpin (Scheme 1 and 2) was determined. Streptavidin was immobilized via standard amine coupling of EDC (1-ethyl-3[3-dimethylaminopropyl]carbodiimide hydrochloride) and NHS (N-hydroxy succinimide) onto both channels of a Carboxymethyl Dextran sensor chip. Biotinylated DNA samples were captured over the sample channel only at a concentration of $200 \mu \mathrm{M}$ in running buffer. The surface was then blocked over both channels by injecting biotin for 2 minutes. Sensorgrams were collected by injecting dilutions of $\mathrm{Zn}$ (II) complexes in $0.10 \mathrm{M} \mathrm{NaCl}, 0.020 \mathrm{M}$ HEPES, pH 7.5 and $0.05 \%$ tween over the sample and reference channels at $25 \mu \mathrm{L} /$ minute. Data overlays were performed using Scrubber 2.0a (Biologic Software Pty, Australia). The data were double referenced using the reference channel along with buffer blank injections. Kinetic data were fit either to a 1:1 binding model or a 2-site model. Langmuir isotherms were also obtained.

\subsection{Isothermal titration calorimetry (ITC)}

Samples contained SS-T4 ( $25 \mu \mathrm{M}$ DNA, $0.080 \mathrm{M} \mathrm{NaCl}$ and 0.020 M HEPES pH 7.5, 25 $\left.{ }^{\circ} \mathrm{C}\right)$. The $\mathrm{Zn}(\mathrm{DL}), \mathrm{Zn}(\mathrm{ML})(4 \mathrm{mM})$ and $\mathrm{Zn}(\mathrm{SL})(1.5 \mathrm{mM})$ titrant had identical salt and buffer conditions as the DNA samples. The titrant was added in $7 \mu \mathrm{L}$ aliquots with a 270 second delay between each injection. The $\mathrm{Zn}(\mathrm{DL})$ titrant was titrated into a buffer solution under identical conditions and was subtracted to eliminate background in the absence of DNA. The titrations were carried out on a MicroCal VP-ITC MicroCalorimeter and data fit to Equations S1 and S2 using Origin software.

\subsection{Thermal Melts $\left(T_{m}\right)$}

All samples contained $2 \mu \mathrm{M}$ duplex, $0.080 \mathrm{M} \mathrm{NaCl}$ and 0.020 M HEPES buffer, $\mathrm{pH}$ 7.5. Data was recorded every $0.5^{\circ} \mathrm{C}$ at a $0.5^{\circ} \mathrm{C} / \mathrm{min}$ ramp rate over the temperature range of $\sim 25-90$ ${ }^{\circ} \mathrm{C}$. Reverse optical melts $\left(90^{\circ} \mathrm{C}\right.$ to $\left.25^{\circ} \mathrm{C}\right)$ gave similar results for duplex DNA. Varying concentrations of $\mathrm{Zn}(\mathrm{DL})$ showed a decrease in thermal melt temperature $\left(\mathrm{T}_{\mathrm{m}}\right)$ of $\mathrm{D}-4$ duplex. A 
Beckman-Coulter DU 640 series UV-vis with Peltier temperature control was used to obtain data. OriginPro 7.5 software was used to analyze the data.

\section{Acknowledgements}

JRM thanks the NSF (CHE-0911375) and (CHE-1262771) for support of this work. Alexandra Van Hall and Melissa Shively are acknowledged for contributions to native gel studies. Mary Murphy and Philip Page of Reichert Technologies are acknowledged for their assistance with SPR studies.

\section{References}

[1] J.E. Reed, A.A. Arnal, S. Neidle, R. Vilar, J. Am. Chem. Soc. 128 (2006) 5992-5993.

[2] L. Cerasino, M.J. Hannon, E. Sletten, Inorg. Chem. 46 (2007) 6245-6251.

[3] M.R. Gill, J.A. Thomas, Chem. Soc. Rev. 41 (2012) 3179-3192.

[4] B.M. Zeglis, J.A. Boland, J.K. Barton, J. Am. Chem. Soc. 130 (2008) 7530-7531.

[5] B.M. Zeglis, V.C. Pierre, J.K. Barton, Chem Commun. (2007) 4565-4579.

[6] P.M. Takahara, A.C. Rosenzweig, C.A. Frederick, S.J. Lippard, Nature 377 (1995) 649-652.

[7] A.C. Komor, J.K. Barton, Chem. Commun. 49 (2013) 3617-3630.

[8] Y. Tanaka, S. Oda, H. Yamaguchi, Y. Kondo, C. Kojima, A. Ono, J. Am. Chem. Soc. 129 (2007) 244-245.

[9] S. Aoki, E. Kimura, Chem. Rev. 104 (2004) 769-788.

[10] E. Kikuta, M. Murata, N. Katsube, T. Koike, E. Kimura, J. Am. Chem. Soc. 121 (1999) 5426-5436.

[11] S.A. Sander, A.K. Van Hall, J.R. Morrow, Inorg. Chem., 54 (2015) 3084-3086.

[12] D.L. Boger, J.-H. Chen, K.W. Saionz, J. Am. Chem. Soc. 118 (1996) 1629-1644.

[13] D.L. Boger, M.W. Ledeboer, M. Kume, M. Searcey, Q. Jin, J. Am. Chem. Soc. 121 (1999) $11375-11383$.

[14] J.L. Leroy, X.L. Gao, V. Misra, M. Gueron, D.J. Patel, Biochemistry 31 (1992) 1407-1415. 
[15] R.S. Lokey, Y. Kwok, V. Guelev, C.J. Pursell, L.H. Hurley, B.L. Iverson, J. Am. Chem. Soc. 119 (1997) 7202-7210.

[16] A.E. Friedman, J.C. Chambron, J.P. Sauvage, N.J. Turro, J.K. Barton, J. Am. Chem. Soc. 112 (1990) 4960-4962.

[17] P. Nordell, P. Lincoln, J. Am. Chem. Soc. 127 (2005) 9670-9671.

[18] M. Kogan, B. Nordén, P. Lincoln, P. Nordell, ChemBioChem 12 (2011) 2001-2006.

[19] B. Önfelt, P. Lincoln, B. Nordén, J. Am. Chem. Soc. 121 (1999) 10846-10847.

[20] B. Önfelt, P. Lincoln, B. Nordén, J. Am. Chem. Soc. 123 (2001) 3630-3637.

[21] Z. Kuklenyik, L.G. Marzilli, Inorg. Chem. 35 (1996) 5654-5662.

[22] T. Li, S. Dong, E. Wang, J. Am. Chem. Soc. 132 (2010) 13156-13157.

[23] J. Zhu, L. Wang, W. Jiang, Chem. Commun. 51 (2015) 2903-2906.

[24] P.B. Landon, J. Lee, M.T. Hwang, A.H. Mo, C. Zhang, A. Neuberger, B. Meckes, J.J. Gutierrez, G. Glinsky, R. Lal, Langmuir, 30 (2014) 14073-14078.

[25] A.J. Genot, D.Y. Zhang, J. Bath, A.J. Turberfield, J. Am. Chem. Soc. 133 (2011) 21772182.

[26] M. Shionoya, T. Ikeda, E. Kimura, M. Shiro, J. Am. Chem. Soc. 116 (1994) 3848-3859.

[27] E. Kimura, N. Katsube, T. Koike, M. Shiro, S. Aoki, Supramol. Chem., 14 (2002) 95-102.

[28] K.E. Siters, S.A. Sander, J.R. Morrow, Dalton Trans. (2015) 44, 3708-3716.

[29] I.M.A. del Mundo, M.A. Fountain, J.R. Morrow, Chem. Commun. 47 (2011) 8566-8568.

[30] I.M.A. del Mundo, K.E. Siters, M.A. Fountain, J.R. Morrow, Inorg. Chem., 51 (2012) 54445457.

[31] L.L. O'Neil, O. Wiest, J. Am. Chem. Soc., 127 (2005) 16800-16801.

[32] E. Kinoshita, E. Kinoshita-Kikuta, T. Koike, Anal Biochem, 337 (2005) 154-160.

[33] E. Kinoshita, E. Kinoshita-Kikuta, M. Yoshimoto, T. Koike, Anal Biochem, 380 (2008) 122-127.

[34] E. Kinoshita-Kikuta, E. Kinoshita, T. Koike, Nucl. Acid Res., 30 (2002) e126/121-126. 
[35] T. Koike, T. Gotoh, S. Aoki, E. Kimura, M. Shiro, Inorg. Chim. Acta 270 (1998) 424-432.

[36] C. Janiak, Dalton Trans. (2000) 3885-3896.

[37] C.R. Martinez, B.L. Iverson, Chem. Sci., 3 (2012) 2191-2201.

[38] D. Rentzeperis, K. Alessi, L.A. Marky, Nucleic Acids Research, 21 (1993) 2683-2689.

[39] L.A. Marky, K.S. Blumenfeld, S. Kozlowski, K.J. Breslauer, Biopolymers, 22 (1983) $1247-$ 1257.

[40] J.R. Grunwell, J.L. Glass, T.D. Lacoste, A.A. Deniz, D.S. Chemla, P.G. Schultz, J. Am. Chem. Soc. 123 (2001) 4295-4303.

[41] C.A. Hunter, H.L. Anderson, Angew Chem Int Ed Engl, 48 (2009) 7488-7499.

[42] C.S. Rossiter, R.A. Mathews, J.R. Morrow, Inorg. Chem. 44 (2005) 9397-9404.

[43] M.O.F. Khan, M.S. Levi, B.L. Tekwani, S.I. Khan, E. Kimura, R.F. Borne, Antimicrobial Agents and Chemotherapy, 53 (2009) 1320-1324. 